\title{
At the interface between signaling and executing anaphase-Cdc14 and the FEAR network
}

\author{
Damien D'Amours and Angelika Amon ${ }^{1}$ \\ Center for Cancer Research, Howard Hughes Medical Institute, Massachusetts Institute of Technology, Cambridge, \\ Massachusetts 02139, USA
}

\begin{abstract}
Anaphase is the stage of the cell cycle when the duplicated genome is separated to opposite poles of the cell. The irreversible nature of this event confers a unique burden on the cell and it is therefore not surprising that the regulation of this cell cycle stage is complex. In budding yeast, a signaling network known as the Cdc fourteen early anaphase release (FEAR) network and its effector, the protein phosphatase Cdc14, play a key role in the coordination of the multiple events that occur during anaphase, such as partitioning of the DNA, regulation of spindle stability, activation of microtubule forces, and initiation of mitotic exit. These functions of the FEAR network contribute to genomic stability by coordinating the completion of anaphase and the execution of mitotic exit.
\end{abstract}

\section{Cdc14-at the beginning and the end of anaphase}

The gene encoding Cdc14 was first identified in a seminal genetic screen for genes required for the cell division cycle (CDC genes) in the budding yeast Saccharomyces cerevisiae (Hartwell et al. 1974). In this screen, Hartwell and colleagues (1974) characterized the point of arrest in the cell cycle of $19 c d c$ mutants, thereby providing a global view of the genetic requirements for progression through the cell cycle in eukaryotes. From this analysis, CDC14 emerged as an essential gene mediating cell cycle events after metaphase, but prior to cytokinesis. Our understanding of the cellular functions of Cdc14 has expanded dramatically in the last $30 \mathrm{yr}$ since its discovery. The CDC14 gene has been cloned and shown to encode the founding member of a novel family of dual specificity Ser/Thr phosphatases (Wan et al. 1992), and although the Cdc14 protein contains sequences in addition to its phosphatase domain, all of its currently

[Keywords: Cdc14; FEAR network; mitotic exit network; anaphase; spindle midzone; chromosome segregation]

${ }^{1}$ Corresponding author.

E-MAIL angelika@mit.edu; FAX (617) 258-6558.

Article and publication are at http://www.genesdev.org/cgi/doi/10.1101/ gad. 1247304 . known functions depend on its phosphatase activity. In recent years, it has been shown that this phosphatase is required for the execution of multiple anaphase events, with its most prominent function being the inactivation of cyclin-dependent kinases (CDKs) during exit from mitosis (Visintin et al. 1998; Jaspersen et al. 1998).

Cdc14 activity is tightly regulated. The phosphatase is bound to an inhibitor, Cfil/Net1, which keeps it inactive in the nucleolus for most of the cell cycle. However, from early anaphase until telophase, the interaction between the two proteins is lost and Cdc14 becomes active. The loss of association between Cdc14 and Cfil/ Net1 is paralleled by a release of Cdc14 from the nucleolus into the nucleus and cytoplasm (Shou et al. 1999; Visintin et al. 1999). At the time of discovery of Cfil/ Net1, it was also found that Cdc14 release from its inhibitor is mediated by the mitotic exit network (MEN), a group of proteins forming a Ras-like signaling cascade (Bardin and Amon 2001; McCollum and Gould 2001; Simanis 2003). However, 2 yr ago, work from several laboratories showed that Cdc14 is also activated by a network of proteins distinct from the MEN, which has been termed the Cdc fourteen early anaphase release (FEAR) network (Fig. 1; Pereira et al. 2002; Stegmeier et al. 2002; Yoshida et al. 2002; Sullivan and Uhlmann 2003). Recent studies have shown that Cdc14 released by this network mediates key anaphase functions distinct from those mediated by the MEN. These include the regulation of chromosome structure and segregation, the regulation of microtubule forces and spindle stability, and the regulation of protein localization. This review focuses on these recently discovered roles of Cdc14 activated by the FEAR network, and discusses how these functions allow the cell to coordinate anaphase events. Beforehand, we will briefly introduce the components of the MEN and FEAR network. Detailed information on MEN components can be found in recent reviews by Bardin and Amon (2001) and Simanis (2003).

The mitotic exit network-mediating the late appearance of Cdc14 in the cell cycle

When the term mitotic exit network was coined (Jaspersen et al. 1998), it referred to a group of genes that, 


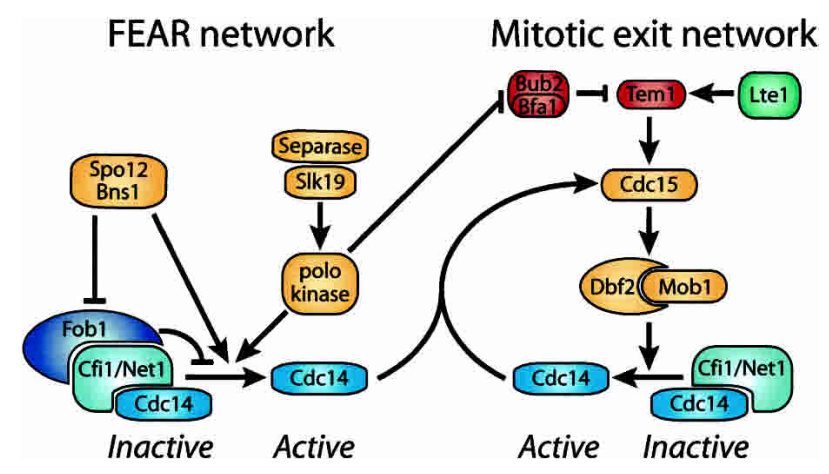

Figure 1. The Cdc14-activating networks. Schematic representation of the functional relationship among the members of the MEN and FEAR network. The ultimate function of these networks is to activate Cdc14 by releasing it from its inhibitor Cfi1/Net1. Lines ending with an arrowhead indicate the stimulation of the downstream effector, whereas lines ending with a perpendicular bar indicate the inhibition of the target protein.

when mutated, cause cells to arrest in late anaphase with high levels of mitotic CDK (Clb-CDK in yeast) activity (Surana et al. 1993; Shirayama et al. 1994; Toyn and Johnston 1994; Jaspersen et al. 1998). Further characterization of this group of genes, guided by studies of the homologous pathway in Schizosaccharomyces pombe, the septation initiation network (SIN), revealed that it constitutes a signaling cascade regulated by a small GTPase, Tem1, and two downstream kinases, Cdc15 and Dbf2-Mob1 (Fig. 1; Table 1; Frenz et al. 2000; Lee et al.
2001; Visintin and Amon 2001). Genetic and biochemical evidence supports a model in which the GTPase Teml functions near or at the top of the MEN and is negatively regulated by a GTPase-activating protein (GAP) complex known as Bub2-Bfa1 and positively regulated by a putative GTP-exchange factor (GEF) Lte1. Bub2-Bfal and Lte1 are members of the MEN but, unlike other MEN components, are not essential for cell viability or MEN activation in an unperturbed cell cycle. The activated form of Tem1, which is likely to be the GTPbound form, is thought to propagate a signal to the protein kinase Cdc15 (Sohrmann et al. 1998). Cdc15 then activates the protein kinase Dbf2, which acts in a complex with Mob1 to activate the MEN (Mah et al. 2001). Activation of the MEN ultimately leads to the release of Cdc14 from its nucleolar inhibitor Cfil/Net1. The molecular details as to how the MEN promotes the dissociation of Cdc14 from Cfil/Net1 are still unclear. However, we do know that Cdc14 mediates the MEN's primary function, that is, the inactivation of Clb-CDK activity and the dephosphorylation of CDK substrates (Visintin et al. 1998).

MEN activity is controlled temporally and spatially through changes in subcelular localization of its components during the cell cycle (Fig. 2). Throughout most of the cell cycle, Bub2 and Bfal colocalize with Tem1 at the spindle pole body (SPB; the yeast equivalent of the mammalian centrosome) destined to migrate into the daughter cell during nuclear division. In contrast, the positive MEN regulator, Lte1, is localized away from Tem 1 in the

Table 1. Names of key anaphase regulators in eukaryotes

\begin{tabular}{|c|c|c|c|c|c|c|}
\hline Generic name & Budding yeast & Fission yeast & Worm & Xenopus & Drosophila & Mammalian \\
\hline & CDC14 & $\operatorname{clp} 1 / f l p 1$ & cdc- 14 & & & CDC14A \\
\hline & & & & & & CDC14B \\
\hline & CFI1/NET1 & & & & & \\
\hline \multirow[t]{11}{*}{ Mitotic CDKs } & CDC28-CLB1， & cdc2-cdc13 & & & & Cdk1-cyclinB, \\
\hline & CDC28-CLB2, & & & & & Cdk1-cyclinA \\
\hline & CDC28-CLB3, & & & & & \\
\hline & CDC28-CLB4 & & & & & \\
\hline & TEM1 & spg1 & & & & \\
\hline & BUB2 & cdc16 & & & & GAPCenA \\
\hline & LTE1 & & & & & \\
\hline & CDC15 & $\operatorname{cdc} 7$ & & & & \\
\hline & DBF2 & sid2 & & & Warts & LATS1 \\
\hline & MOB1 & mob1 & & & MOB1 & MOB1 \\
\hline & & & & & & MOB4 \\
\hline Separase & ESP1 & cut 1 & sep-1 & & $\begin{array}{l}\text { Three Rows (THR) } \\
\text { and Separase (SSE) }\end{array}$ & ESPL1 \\
\hline \multirow[t]{3}{*}{ Securin } & PDS1 & cut2 & IFY-1 & PTTG & Pimples (PIM) & PTTG1 \\
\hline & SPO12/BNS1 & wis3 & & & & \\
\hline & SLK19 & & & & & \\
\hline \multirow[t]{3}{*}{ Polo kinase } & CDC5 & plo1 & plk-2 & PLX1 & POLO & PLK1 \\
\hline & FOB1 & & & & & \\
\hline & SCCI/MCD1 & $\operatorname{rad} 21$ & scc-1 & RAD21 & RAD21 & RAD21/SCC1 \\
\hline \multirow[t]{5}{*}{ Aurora kinase } & IPL1 & ark1 & AIR-1 & Aurora A (Eg2) & Aurora A & Aurora A \\
\hline & & & AIR-2 & Aurora B & Aurora B & Aurora B \\
\hline & & & & & & Aurora C \\
\hline & SLI15 & pic1 & icp-1 & Incenp & Incenp & Incenp \\
\hline & BIR1 & cut17 & bir-1 & Survivin & Survivin & Survivin \\
\hline
\end{tabular}




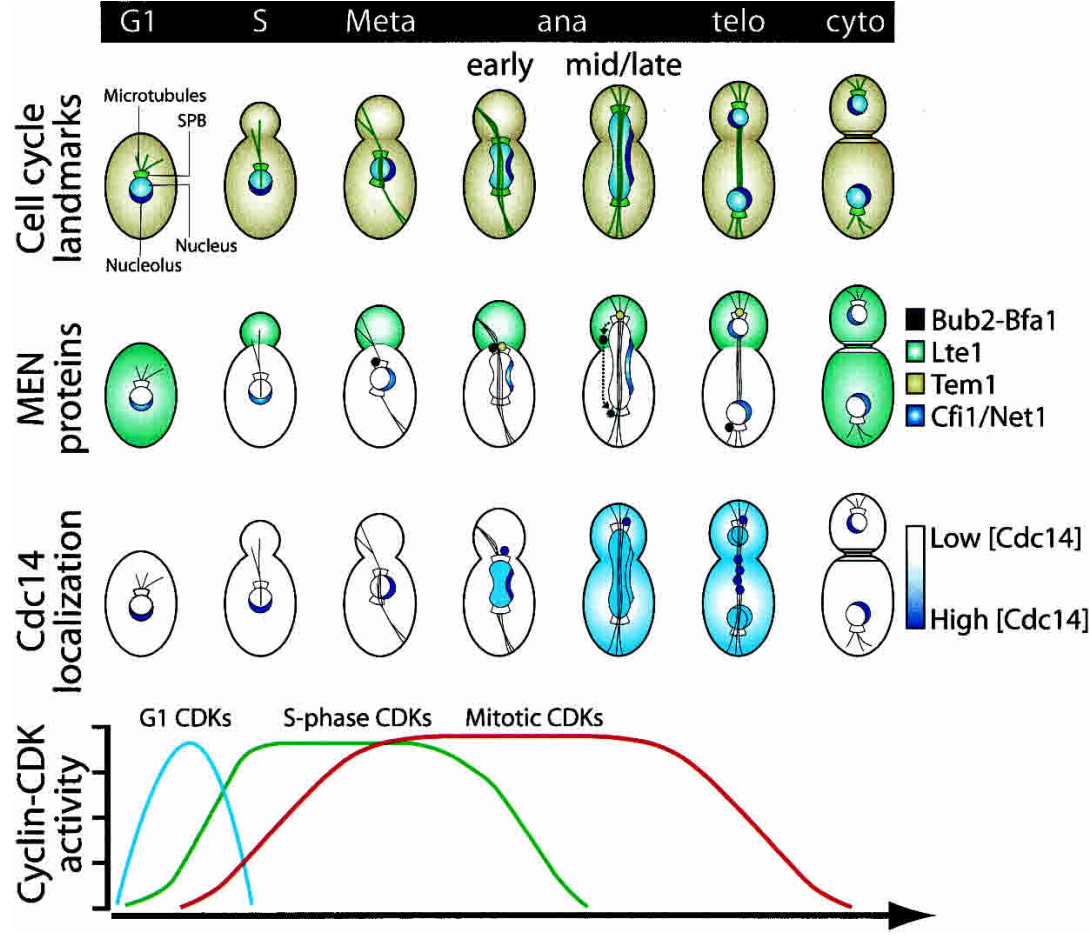

Figure 2. Temporal and spatial regulation of the components of the MEN. The top row of cells illustrates the appearance of cell cycle landmarks as yeast progress from G1 to the end of the cell cycle. The middle row is a schematic representation of the changes in the localization of MEN components at various stages of the cell cycle. A key for the identification of each MEN member is shown on the right of this row. Cdc5, Dbf2, and Mob1 were omitted for simplicity. The bottom row illustrates the localization of Cdc14 throughout the cell cycle. When released from the nucleolus, Cdc14 becomes enriched at specific organelles (dSPB and spindle mizone) in addition to its general localization in the nucleus and cytoplasm. The regions with concentrated Cdc14 are shown in dark blue in the cell diagrams. One of the main functions of Cdc14 released by the MEN is to inactivate cyclin-CDK activity. The graph at the bottom shows how the changes in MEN components localization correlate with changes in the levels of cyclin-CDK activity throughout the cell cycle. Figure modified from Bardin and Amon (2001; Fig. 3 and Box 1) with permission from Nature Reviews Molecular Cell Biology. (C) 2001 Macmillan Magazines Ltd.) bud (Bardin et al. 2000; Pereira et al. 2000). The close association of Tem1 to its GAP Bub2-Bfal maintains it in its inactive GDP-bound form. However, when the spindle elongates during anaphase, the Tem1-bearing SPB enters the bud where the MEN positive regulator Lte1 is concentrated (Bardin et al. 2000; Pereira et al. 2000). Post-translational modifications occurring on Bub2-Bfa1 during anaphase also suggest that the GAP activity of the complex is inactivated when the daughter-bound SPB (dSPB) enters the bud (Hu et al. 2001; Pereira et al. 2002). Concomitantly with penetration of the dSPB into the bud during anaphase, Cdc15 becomes enriched at the Tem1-bearing SPB, whereas Bub2-Bfa1 relocalize to the SPB in the mother cell (Molk et al. 2004). Therefore, the passage of the dSPB through the bud neck during anaphase appears to mark a switch from an inactive MEN to an active MEN.

\section{Anxious to release Cdc14-the FEAR network}

The existence of an additional pathway regulating Cdc14 during anaphase became apparent through the observation that Cdc14 was still released from the nucleolus in cells lacking MEN activity. This release occurs transiently during early anaphase when the mitotic spindle is elongating from 4 to $7 \mu \mathrm{m}$, a process that takes between 5 and $10 \mathrm{~min}$ in yeast (Pereira et al. 2002; Stegmeier et al. 2002; Yoshida et al. 2002; Sullivan and Uhlmann 2003). Factors required for this transient release of Cdc14 were subsequently identified (discussed below) and are collectively referred to as the FEAR network. The FEAR network-mediated release of Cdc14 differs from that mediated by the MEN in that (1) it does not occur throughout the cell, but is restricted to the nucleus, and (2) it cannot promote Clb-CDK inactivation and exit from mitosis (Stegmeier et al. 2002). This fact, however, should not be taken as an indication of a lesser importance of the FEAR network. Indeed, progression through anaphase in the absence of FEAR network activity is associated with a significant loss in viability (D'Amours et al. 2004).

To date, we know of five proteins that function in a positive manner in the FEAR network and of two that function in an inhibitory fashion. Positive factors are Separase (Esp1 in budding yeast), the kinetochore/ spindle protein Slk19, Spo12 and its close homolog Bns1, and the polo kinase Cdc5 (Table 1; Stegmeier et al. 2002; Visintin et al. 2003). The negative factors are Securin (Pds1 in yeast), an inhibitor of Separase, and the nucleolar protein Fob1 (Cohen-Fix and Koshland 1999; TinkerKulberg and Morgan 1999; Sullivan and Uhlmann 2003; Stegmeier et al. 2004). Separase encodes a protease that is best known for its role in sister-chromatid separation. The protease cleaves a component of cohesin, the protein complex that holds sister chromatids together, thereby triggering chromosome segregation (for review, see Nasmyth 2002). Esp1/Separase is also required for Cdc14 release from the nucleolus as a component of the FEAR network, yet surprisingly, its protease activity appears not to be required to mediate its FEAR network function (Sullivan and Uhlmann 2003). Consistent with this, the anaphase-specific cleavage of Slk19, another FEAR network component, by Esp1/Separase is not required for Cdc14 release from the nucleolus (Stegmeier et al. 2002; Sullivan and Uhlmann 2003). It is thought 
that rather than cleavage of Slk19 by Esp1/Separase being important for FEAR network function, it is the ability of Slk19 to target Esp1/Separase to the spindle midzone and vice versa that may be important for Cdc14 release (Sullivan et al. 2001; Sullivan and Uhlmann 2003). Identifying the protease-independent function of Esp1/Separase in exit from mitosis and the role of Slk19 in the FEAR network will be an important task in the future. From a regulatory point of view, it is interesting to note that the Esp1/Separase inhibitor Pds1 inhibits both Esp1/Separase's protease function in promoting sister chromatid separation and its nonproteolytic (FEAR network-related) function (Sullivan and Uhlmann 2003). This finding explains why Cdc14 early anaphase release from the nucleolus can be inhibited by the spindle checkpoint, which prevents Esp1/Separase activation by inhibiting the degradation of Securin (Stegmeier et al. 2002; Yoshida et al. 2002). The fact that Securin inhibits FEAR network function also indicates that the FEAR network can be inhibited by the DNA damage checkpoint, which prevents entry into anaphase by inhibiting Pds1 degradation (Cohen-Fix et al. 1996).

The polo kinase Cdc5 acts at multiple stages during mitotic exit, which makes the dissection of its role in the FEAR network difficult. Nevertheless, it is clear that Cdc5 is a component of the FEAR network and a regulator of the MEN. Cdc5 contributes positively to the MEN by negatively regulating the Tem1 inhibitor complex Bub2-Bfal (Hu et al. 2001) and by stimulating Cdc15 kinase activity (via the FEAR network; Stegmeier et al. 2002). The molecular function of Cdc5 in the FEAR network and whether its kinase activity is required for Cdc14 activation in early anaphase is not known. However, it is possible, if not likely, that Cdc5's kinase activity is required for FEAR network function, as several studies suggest that Cdc5 promotes the phosphorylation of Cfil/Net1 and Cde14 (Shou et al. 2002; Yoshida and Toh-e 2002; Visintin et al. 2003).

Spo12 and Bns1 are both small proteins with no known enzymatic activity. However, recent studies suggest that a small conserved domain (residues 117-137) within Spo12 is important for mediating the protein's FEAR network function, perhaps by serving as a proteinprotein interaction domain (Shah et al. 2001; Stegmeier et al. 2004). Spo12 is a nucleolar phosphoprotein that binds to an inhibitor of the FEAR network, Fob1. Because Fob1 also binds to Cfil/Net1 and prevents Cdc14 release, it has been proposed that Spo12 can induce an anaphase-specific conformational switch in Fob1 that would reduce its ability to inhibit Cdc14 release (Stegmeier et al. 2004). In this scenario, mitotic phosphorylation of Spo12 could be the trigger for this conformational change in Fob1, which would, in turn, affect the interaction between Cfil/Net1 and Cdc14.

\section{A model for the relationship among FEAR network components}

Our knowledge of the relationship among FEAR network components is mainly of a genetic nature, and therefore limited. The key observations of these genetic epistasis experiments are as follows. The defect in Cdc14 release from the nucleolus of $\operatorname{sik} 19 \Delta$ and esp1-1 single mutants is similar to that of the slk19s esp1-1 double mutant, suggesting that the two proteins function in the same pathway (Visintin et al. 2003). Furthermore, Slk19 is required for Cdc14 release from the nucleolus caused by overexpression of Esp1 (Sullivan and Uhlmann 2003; Visintin et al. 2003), suggesting that Slk19 either functions downstream of, or together with Esp1 in accomplishing this task. The fact that overexpression of Cdc5 or Spo12 alleviates the need for both Slk19 and Esp1 in promoting Cdc14 release from the nucleolus formally places Cdc5 and Spo12 downstream of, or in parallel to Esp1 and Slk19 (Visintin et al. 2003). However, owing to the fact that Cdc5 functions in both the MEN and the FEAR network, the results of these epistasis analyses must be interpreted with caution. The release of Cdc14 from the nucleolus induced by Cdc 5 overexpression is much stronger than that induced by Spo12, which is consistent with Cdc5 activating not only the FEAR network, but also the MEN (Visintin et al. 2003).

Double-mutant analysis also suggests that Spo12 functions in parallel to the Esp1-Slk19 branch. The defect in Cdc14 release from the nucleolus is more severe in

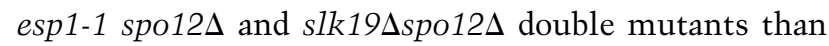
in the single mutants. Cdc5 also appears to act independently of Spo12 and vice versa, as overexpression of either Cdc5 or Spo12 in cells lacking the other protein induces the release of Cdc14 from the nucleolus in early anaphase, although the extent of Cdc14 release induced by Spo12 in the absence of Cdc5 is small (Sullivan and Uhlmann 2003; Visintin et al. 2003). It is worth noting that two different approaches were used to determine the epistatic relationship among FEAR network components. In the study by Sullivan et al. (2004), metaphasearrested cells were used, whereas Cdc14 release from the nucleolus was monitored in normal anaphases in the other study (Visintin et al. 2003). The presence of a metaphase inhibitor or the absence of an unidentified anaphase activator of the FEAR network in metaphase-arrested cells might explain why overexpression of Spo12 did not lead to Cdc14 release in one study (Sullivan and Uhlmann 2003).

The results described above are consistent with a model for the functional interactions between FEAR network components. In this model (Fig. 1), the FEAR network is composed of two branches, one including Esp1, Slk19, and the polo kinase Cdc5, whereas the other includes Spo12, Bns1, and Fob1. The action of both branches is necessary to promote Cdc14 release from its inhibitor during early anaphase, although from a molecular perspective, the Esp1-Slk19-Cdc5 branch may affect the Cfil/Net1-Cdc14 interaction differently than the Spo12-Bns1 branch. This model explains why loss of either branch of the network leads to a complete abrogation of Cdc14 release in the absence of MEN (Stegmeier et al. 2002; Visintin et al. 2003) and accommodates the observation that Cdc5 appears to be able to induce phosphorylation of Cdc14 in a MEN-independent man- 
ner. Nevertheless, before the contribution of each FEAR network component is understood at the molecular level, alternative models cannot be excluded.

Why would it be beneficial for the cell to have two or multiple branches in the FEAR network when Spo12 alone can do the job, provided its expression levels are increased (Parkes and Johnston 1992; Molero et al. 1993; Jaspersen et al. 1998)? We hypothesize that this provides an opportunity for integrating cellular events with progression through anaphase. By using a key component of the sister-chromatid separation machinery in the FEAR network (Esp1/Separase), cells make sure that chromosome segregation has initiated before Cdc14 is released from the nucleolus. Yet, at the same time, a dual pathway guarantees that Esp1/Separase is not able to initiate Cdc14 release from the nucleolus on its own, as this could initiate mitotic exit prior to completion of sister chromatid segregation. Therefore, an important function of the FEAR network may be to act as a timer or a buffer between chromosome segregation and cell separation. This could be accomplished by first waiting to obtain a signal from the activated chromosome segregation machinery, and second, by being purposefully slow at releasing Cdc14 from the nucleolus-by keeping Spo12 levels low-so as to make sure that Cdc14 does not initiate mitotic exit prior to anaphase completion. These observations are consistent with the idea that using multiple suboptimal events in the regulation of a given process confers a switch-like response with a built-in delay onto that process-a situation analogous to the degradation of Sicl at the G1-S-phase transition (Nash et al. 2001). Given that no checkpoints have been discovered that monitor the completion of chromosome segregation, this timer function of the FEAR network may be essential to schedule a timely-yet sufficiently lateexit from mitosis.

\section{Molecular mechanism of the FEAR network-mediated Cdc14 release}

Several reports indicate that the association of Cdc14 with its inhibitor is regulated by phosphorylation. In vitro, addition of Clb2-CDK to Cdc14-Cfil/Net1 complexes dissociates them (Shou et al. 2002; Azzam et al. 2004). In vivo, dissociation of Cdc14 from the nucleolus correlates with an increase in phosphorylation of Cdc14 and Cfil/Net1 (Visintin et al. 2003). However, until recently, the molecular details as to how phosphorylation triggered by the MEN and the FEAR network affects this association have remained unknown. A recent report by Azzam et al. (2004) identified three phosphorylation sites within the $\mathrm{N}$ terminus of Cfil/Net1 that are important for controlling the association of Cdc14 with Cfil/Net1 during early anaphase. Mutation of S166, $\mathrm{T} 212$, and S252 to alanine in Cfil/Net1 prevents release of Cdc14 from the nucleolus during early anaphase. Furthermore, cells carrying mutations in all six putative CDK phosphorylation sites in the minimal Cdc14-interaction region of Cfi1/Net1 (T62, S166, T212, S252, T297, T304) exhibit an even greater defect in releasing
Cdc14 from the nucleolus. The Cdc14 release defect exhibited by these Cfil/Netl mutants is highly reminiscent of that of FEAR network mutants, suggesting that the FEAR network promotes Cdc14 release from its inhibitor by promoting phosphorylation of these sites. Consistent with this idea are not only the genetic interactions of this mutant with MEN mutants, but also the fact that phosphorylation of these residues is restricted to anaphase and depends on the FEAR network (Azzam et al. 2004).

Previous studies suggested Cdc5 as another likely candidate for promoting the dissociation of Cdc14 from its inhibitor. Cdc5 is also capable of disassembling the Cdc14-Cfi1/Net1 complex in vitro (Shou et al. 2002); Cdc5 is the only FEAR (or MEN) component yet identified that has the ability to induce $\mathrm{Cdc} 14$ release from the nucleolus in all stages of the cell cycle, even in G1, when Clb-CDK are absent (Visintin et al. 2003; R. Visintin and A. Amon, unpubl.); overexpression of Cdc5 induces phosphorylation of Cdc14 and Cfil/Net1 in vivo (Visintin et al. 2003) and can phosphorylate both proteins in vitro (Shou et al. 2002). However, although these data would implicate Cdc5 in promoting the dissociation of Cdc14 from its inhibitor, the data by Azzam et al. (2004) implicate mitotic CDKs, rather than Cdc5, in phosphorylating Cfil/Net1. First, the six residues whose phosphorylation is important for the dissociation of Cdc14 from its inhibitor fall within the S/T-P motif, which corresponds loosely to the CDK consensus sequence for phosphorylation. Second, cells depleted for the mitotic cyclins $\mathrm{Clb} 1$ and $\mathrm{Clb} 2$ enter anaphase (although with a great delay, because Clb-CDK activity is important for the metaphase-anaphase transition), yet fail to release Cdc14 from the nucleolus and arrest prior to exit from mitosis. These observations led Azzam and colleagues (2004) to conclude that the FEAR network targets Cfil/Net1 for phosphorylation by Clb-CDKs specifically during anaphase.

\section{Functions of the FEAR network}

\section{Initiation of the MEN}

One of the phenotypes of FEAR network mutants is that they delay progression through the cell cycle by $20 \mathrm{~min}$ (i.e., approximately one-fourth of the yeast cell cycle). This delay occurs in late anaphase, as judged by the persistence of $\mathrm{Clb}$ cyclin protein and associated kinase activity and a delay in anaphase spindle disassembly (Stegmeier et al. 2002). The reason for this delay in exit from mitosis is that Cdc14 released by the FEAR network has the ability to act in a feed-forward amplification loop to activate itself by activating the MEN (Figs. 1, 3). Many MEN components are phosphoproteins, and in the case of the MEN component Cdc15, phosphorylation has been shown to be inhibitory (Jaspersen and Morgan 2000). Interestingly, Cdc15 is transiently dephosphorylated during anaphase (Visintin and Amon 2001). In FEAR network mutants, Cdc15 is not dephosphorylated during early anaphase and MEN activation, as judged by 


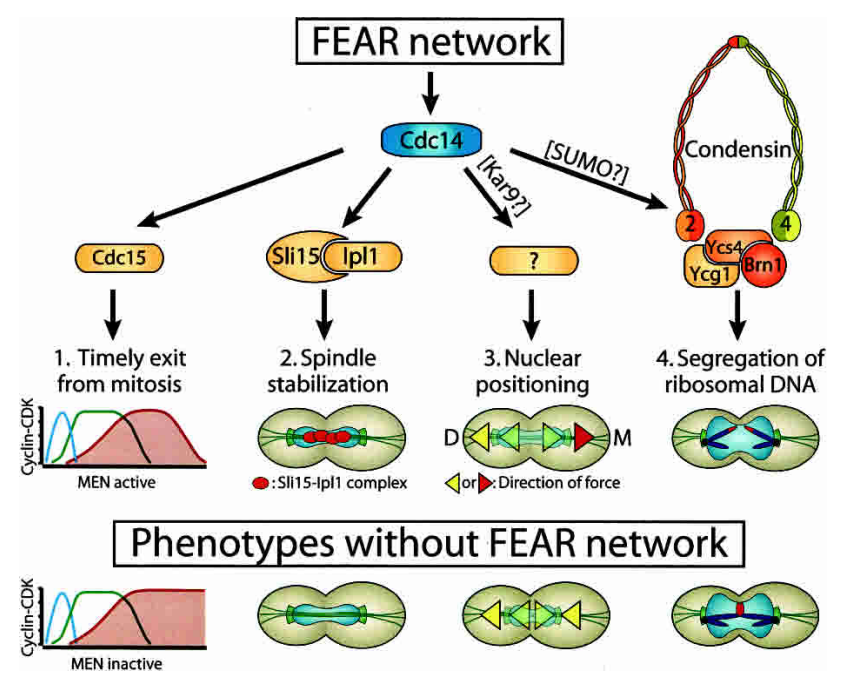

Figure 3. The FEAR network is a central regulator of anaphase events. Schematic representation of the known functions of the FEAR network. The proteins depicted immediately below Cdc14 are the downstream effectors of the FEAR network in each process. Both Cdc15 and Sli15 are direct targets of Cdc14 in vitro. Dephosphorylation of Cdc15 is believed to stimulate its kinase activity, whereas dephosphorylation of Sli15 directs the Ipl1-Sli15 complex to the spindle midzone. Cdc14 also targets the condensin complex to the nucleolus, but this event is unlikely to result directly from Cdc14-mediated dephosphorylation of the complex. The immediate target of Cdc14 in this process is currently unknown, but may involve components of the sumoylation machinery. Likewise, the effector of the nuclear positioning function of Cdc14 is still unknown but may be Kar9. Furthermore, it remains a formal possibility that the FEAR network does not act through Cdc14 in the regulation of nuclear positioning. The characters $\mathrm{D}$ and $\mathrm{M}$ on each side of the anaphase cell in the third column refer to the daughter and mother portions of the cell, respectively, and the red arrowhead indicates the microtubule force stimulated by the FEAR network.

measurements of kinase activity associated with the most downstream MEN component, Dbf2, is reduced (Stegmeier et al. 2002). Furthermore, expression of a Cdc15 mutant that can no longer be phosphorylated on specific CDK sites suppressed FEAR network mutant defects (Stegmeier et al. 2002). It is likely that Cdc14 released by the FEAR network regulates other MEN components beside Cdc15. The MEN components Bfal and Lte1 have also been shown to be Cdc14 substrates in vitro, and dephosphorylation of these has been suggested to affect their function and localization, respectively (Pereira et al. 2000, 2002; Jensen et al. 2002; Seshan et al. 2002).

Together, these observations are consistent with a model in which Cdc14 released from the nucleolus by the FEAR network stimulates its own release by activating the MEN, thereby initiating a positive feedback loop. Dephosphorylation of Cdc15 and perhaps other MEN components by Cdc14 could increase the affinity of Tem1-GTP to Cdc15, or even allow some MEN activation in the absence of active Tem1. However, full MEN signaling cannot occur solely through dephosphorylation of Cdc15, as a phosphorylation-resistant mutant of Cdc15 does not alleviate the mitotic exit defect of a strain deleted for TEM1 (Jaspersen and Morgan 2000). Determining the mechanism whereby Cdc14 stimulates MEN activity will be an important question for future work.

\section{Regulation of anaphase spindle stability}

The middle part of the mitotic spindle, the spindle midzone, is particularly fragile during anaphase. The rapid elongation of the spindle that occurs in this phase of the cell cycle reduces the overlap between the pole-to-pole microtubules to a critically small region of the spindle (Byers and Goetsch 1975; Winey et al. 1995). Therefore, it is perhaps not surprising that spindle stabilization factors localize to the spindle midzone during anaphase. Interestingly, stabilization of the spindle midzone during anaphase appears to be under the control of two FEAR network components, Separase and Slk19. The absence of either factor causes a collapse of the anaphase spindle (Zeng et al. 1999; Sullivan et al. 2001), raising the possibility that one function of the FEAR network is to stabilize the anaphase spindle. Recent data by Pereira and Schiebel (2003) confirmed this suspicion and provided insight into the mechanism whereby the FEAR network contributes to anaphase spindle stability. The FEAR network appears to act by targeting the evolutionarily conserved Ipl1-Sli15-Bir1 complex to the spindle midzone, where it then promotes the activity of spindle-stabilizing factors.

The Ipl1-Sli15-Bir1 complex is homologous to the Aurora B-Incenp-Survivin complex of higher eukaryotes. The complex is required for several aspects of mitotic spindle regulation, including bipolar attachment of kinetochores to the spindle (Tanaka et al. 2002), activation of the spindle tension checkpoint (Biggins and Murray 2001), and mitotic spindle disassembly (Buvelot et al. 2003). In addition, the complex has recently been shown to regulate anaphase-specific chromosome condensation (Petersen and Hagan 2003; Lavoie et al. 2004). The subcellular localization of the Ipll complex is dynamic during the cell cycle, associating with kinetochores prior to metaphase and then localizing to the spindle midzone during anaphase (Zeng et al. 1999; Sullivan et al. 2001; Buvelot et al. 2003; Pereira and Schiebel 2003). The FEAR network is essential for the translocation of Ipl1 and Sli15 to the spindle midzone in early anaphase (Pereira and Schiebel 2003). However, in the absence of FEAR network activity, Sli15 eventually localizes to the spindle midzone in late anaphase in a MEN-dependent manner, suggesting that this function is shared between the FEAR network and the MEN.

How does the FEAR network promote the translocation of the Ipl1 complex to the spindle midzone? Sli15 is a phosphoprotein with multiple CDK consensus phosphorylation sites. Pereira and Schiebel (2003) showed that Sli15 is partially dephosphorylated during anaphase in a Cdc14-dependent manner and binds directly via its 
microtubule-binding domain to Cdc14, thereby providing a potential mechanism for the regulation of the Ipl1 complex by the FEAR network (Pereira and Schiebel 2003). Mutation of the putative CDK phosphorylation sites to residues that can no longer be phosphorylated bypasses the requirements for the FEAR network in the association of Sli15 to the spindle midzone. Furthermore, the phosphorylation-site mutant of Sli15 stabilizes mitotic spindles formed in the absence of Esp1/ Separase activity, which normally break down in anaphase (Sullivan et al. 2001; Pereira and Schiebel 2003). Interestingly, a report by Buvelot et al. (2003) showed that during anaphase, Ipll destabilizes the mitotic spindle rather than stabilizing it. The reason for these seemingly contradictory results may be that Pereira and Schiebel (2003) examined the effects of Sli15 in metaphase-arrested cells that were induced to undergo anaphase by artificial cleavage of cohesin, whereas Buvelot and colleagues (2003) analyzed the effects of Ipll in cells undergoing a normal anaphase. Perhaps metaphase cells contain spindle-destabilizing factors that are antagonized by targeting of the Ipl1 complex to the spindle midzone.

How does the Ipl1 complex promote anaphase spindle stabilization? An attractive hypothesis is that the complex promotes the translocation of microtubule stabilization factors to the midzone. A candidate target is the kinetochore/spindle-binding factor Slk19. Slk19, like the Ipll complex, translocates to the spindle midzone during anaphase (Zeng et al. 1999). This transition to the spindle midzone during anaphase requires both the FEAR network and Ipl1-Sli15. Expression of a mutant form of Sli15 that can no longer be phosphorylated partially suppresses the need for the FEAR network in this process (Pereira and Schiebel 2003). Taken together, these observations indicate that $\mathrm{Cdc} 14$ released from the nucleolus by the FEAR network (along with the MEN) targets the Ipll complex to the spindle midzone, where it in turn mediates the recruitment of the spindle-stabilizing protein Slk19. How the Ipll complex mediates this function is still unclear, but it appears likely that this would involve an Ipl1-dependent phosphorylation of either Slk19 or a targeting protein for Slk19. Interestingly, not all spindle midzone proteins are mislocalized in ipl1 or sli15 mutants; the spindle-stabilizing protein Ase1, for example, is correctly targeted at the midzone in sli15 mutants (Pereira and Schiebel 2003).

An important question is why are spindles still stable in the absence of Slk19 targeting to their midzone (i.e., in sli15 or cdc14 mutants) when complete loss of Slk19 causes spindle collapse? Pereira and Schiebel (2003) suggest that this apparent paradox is caused by the fact that the reduced levels of Slk19 protein still in contact with the spindle (without being specifically targeted at the midzone) in sli15 or cdc14 mutants are sufficient to provide some stabilizing function to the spindle. This partial function is dependent on the stabilizing function of Ase1, because loss of both Slk19 and Ase1 targeting to the midzone in esp1/separase mutants causes spindle collapse (Sullivan et al. 2001). The ability of either Ase1 or Slk19 to suppress the spindle collapse phenotype of the other when it is not targeted to the spindle midzone appears to be reciprocal. This idea is supported by the observation that expression of the phosphorylation site mutant of Sli15 in esp1/separase-deficient cells allows the formation of stable spindles in the absence of Ase1 localization to the spindle midzone (Pereira and Schiebel 2003). Given the importance of the spindle midzone and the cell midbody in cytokinesis in higher eukaryotes, it will be important to evaluate the importance and potential conservation of the midzone-targeting functions of the FEAR network in mammalian cells.

\section{Nuclear positioning}

The FEAR network not only regulates spindle stability, but also forces exerted by cytoplasmic microtubules (cMTs) during anaphase. These FEAR network-dependent cMT-directed forces play an important role in positioning the dividing nucleus so that the mother and daughter cells will each receive their proper half of the duplicated genome. The identification and characterization of MT forces is usually complicated by the fact that multiple forces act on the nucleus during mitosis. However, in an elegant study, Ross and Cohen-Fix (2004) identified a previously unappreciated FEAR network-dependent nucleus-pulling force mediated by cMTs in the mother cell.

The initial suggestion as to the existence of a nucleuspulling force exerted specifically by cMTs from the mother side of the dividing cell came from the observation that the nucleus is always pulled into the daughter cell (the bud) in esp1/separase mutants (McGrew et al. 1992). This preference for the migration of the undivided nucleus into the future daughter cell, called the "daughterly" phenotype, is the combined result of the inability of esp1/separase mutants to segregate their DNA and their FEAR network defect (Ross and Cohen-Fix 2004). However, these two defects are independent of each other. Nevertheless, the reason why these two functions have to be lost to visualize the daughterly phenotype is that they both contribute semiredundant forces in the positioning of the nucleus during anaphase. On the one hand, elongation of the mitotic spindle provides a force that pushes the dividing nucleus into both the bud and the mother sides of the cell. In the absence of chromosome segregation, spindle elongation is prevented and the only forces that can move the nucleus within these mutant cells must be exerted by cMTs. Ross and CohenFix (2004) proposed that the FEAR network is specifically required for the activation of pulling forces exerted by cMTs in the mother side of the cell. This was demonstrated in an experiment in which preventing sister chromatid segregation while maintaining FEAR activity (in a mutant expressing a noncleavable version of the cohesin Scc1/Mcd1) allowed the undivided nucleus to remain in the mother cell. Conversely, inactivation of the FEAR network in cells expressing the noncleavable version of Scc1/Mcd1 leads the undivided nucleus to be pulled into the bud, thereby recapitulating the esp1/ separase phenotype (Ross and Cohen-Fix 2004). Interest- 
ingly, artificial release of Cdc14 (using the dominant TAB6-1 allele of the gene) did not fully restore the nuclear positioning phenotype of FEAR network mutants, suggesting that Cdc14 might not be the sole effector of the FEAR network in this process. However, it is also possible that the Tab6-1 protein cannot perform all Cdc14 functions, an alternative consistent with the finding that the phosphatase activity of the mutant enzyme is reduced to $\sim 75 \%-80 \%$ of wild-type levels (Shou et al. 2001).

What could be the target of Cdc14 in this process? A key candidate is the adenomatous polyposis coli (APC)related protein Kar9. Kar9 is a microtubule-associated protein that binds the daughter-bound SPB and translocates to cytoplasmic microtubules during mitosis (Liakopoulos et al. 2003; Maekawa et al. 2003). Kar9 localization to the SPB that remains in the mother cells appears to be inhibited by Clb4-CDK, although the extent with which Kar9 phosphorylation confers its asymmetric localization is controversial (Liakopoulos et al. 2003; Maekawa and Schiebel 2004). Cdc14 released by the FEAR network may reverse CDK phosphorylation on Kar9 during early anaphase, thereby inducing the localization of Kar9 to the SPB in the mother cells, where it could stimulate the pulling force on the cytoplasmic microtubules in the mother cell. Consistent with this view, phosphorylation of Kar9 is reduced specifically in early anaphase (Liakopoulos et al. 2003; Maekawa et al. 2003). It is, however, important to note that many microtubuleassociated motor proteins are phosphorylated by $\mathrm{Clb}-$ CDKs during mitosis (Ubersax et al. 2003) and represent alternative or additional potential targets for Cdc14 in nuclear positioning.

Taken together, these observations are consistent with a new model for the regulation of nuclear positioning during mitosis (Ross and Cohen-Fix 2004). Prior to anaphase, cMTs in the mother cell push the nucleus toward the bud neck with the help of pulling forces exerted by cMTs anchored in the bud (Fig. 3; Pearson and Bloom 2004). At the onset of anaphase, the FEAR network switches the direction of the forces exerted by cMTs anchored in the mother cell cortex from pushing to pulling. This, together with the pushing forces provided by the elongating spindle, allows half of the nucleus to move back to the mother cell. The other half migrates into the bud in response to the combined action of the pulling forces exerted by cMTs anchored in the bud cortex and the elongating spindle.

\section{Segregation of repetitive DNA in mitosis and meiosis}

Loss of sister-chromatid cohesion is a multistep process leading to the inactivation of cohesin, the ring-shaped protein complex that holds sister chromatids together from S phase to metaphase (for review, see Nasmyth 2002). At the metaphase-anaphase transition, proteolytic cleavage of the Scc1/Mcd1 subunit of cohesin by Separase is believed to open the cohesin ring, thereby allowing sister chromatids to move to opposite poles of the cell. Recent work has revealed an unexpected role for the FEAR network in chromosome segregation, specifically in the segregation of heterochromatic/repetitive regions of the genome. The identification of this role has challenged the hitherto held view that cohesin mediates all biologically relevant chromosomal linkages during cell division. Striking parallels between observations in yeast and in higher eukaryotes suggest that at least some aspects of this function of the FEAR network will be conserved across species.

Studies on the fruit fly Drosophila melanogaster have provided the most compelling evidence for the existence of additional modes of chromosome association-or persistent cohesion - at heterochromatic and repeated loci. For instance, it has long been known that in metaphasearrested Drosophila cells, cohesion between sister chromatid arms is lost for all chromosomes except the heterochromatic $\mathrm{Y}$ chromosome, where sister chromatids remain paired along their entire length (Fig. 4A; Gonzalez et al. 1991). In fact, the persistent cohesion at heterochromatic loci has been used for many years as a cytological marker for studies of chromosome rearrangement and segregation in flies (see Fig. 4D; Pimpinelli and Ripoll 1986). More recently, Drosophila heterochromatic dodecasatellite DNA has also been found to maintain a physical connection between prematurely separated sister chromatids or so-called "ski anaphases" (Carmena et al. 1993). Finally, during Drosophila female meiosis, heterochromatic regions of achiasmate homologs (some chromosomes in Drosophila females do not undergo meiotic recombination) remain paired until metaphase, whereas euchromatic regions separate earlier in prophase (Dernburg et al. 1996; Karpen et al. 1996).

Persistent cohesion at heterochromatic and repeated DNA has also been observed in other eukaryotes. For instance, it has been found at the beginning of the last century that the nucleolus-the organelle containing the heterochromatic ribosomal DNA (rDNA) - in the yeast Schizosaccharomyces octosporus separates much later than the rest of the nucleus in meiosis (Fig. 4C; Guilliermond 1917). This observation has been confirmed more recently using molecular tools in the budding yeast Saccharomyces cerevisiae (Granot and Snyder 1991; Buonomo et al. 2003). The repetitive, heterochromatinlike telomeres have also been found to separate later than other sequences in budding yeast (Straight et al. 1997). In mammalian cells, chromosomes containing the largest amount of pericentric heterochromatin are always the last to separate in anaphase (Fig. 4C; Vig 1982; for review, see Vig 1987). Furthermore, repetitive sequences such as human or mouse pericentric satellite DNA and sections of the Y chromosome in fly can be moved to other genomic locations and confer onto these a late-segregating behavior and increase their rate of nondisjunction (Fig. 4E,F; Lica et al. 1986; Pimpinelli and Ripoll 1986; Gonzalez et al. 1991; Warburton and Cooke 1997; Rudd et al. 2003). Taken together, these observations suggest that the segregation of at least some repetitive/heterochromatic sequences requires different and/ or additional mechanism(s) than that of early-segregating sequences. 

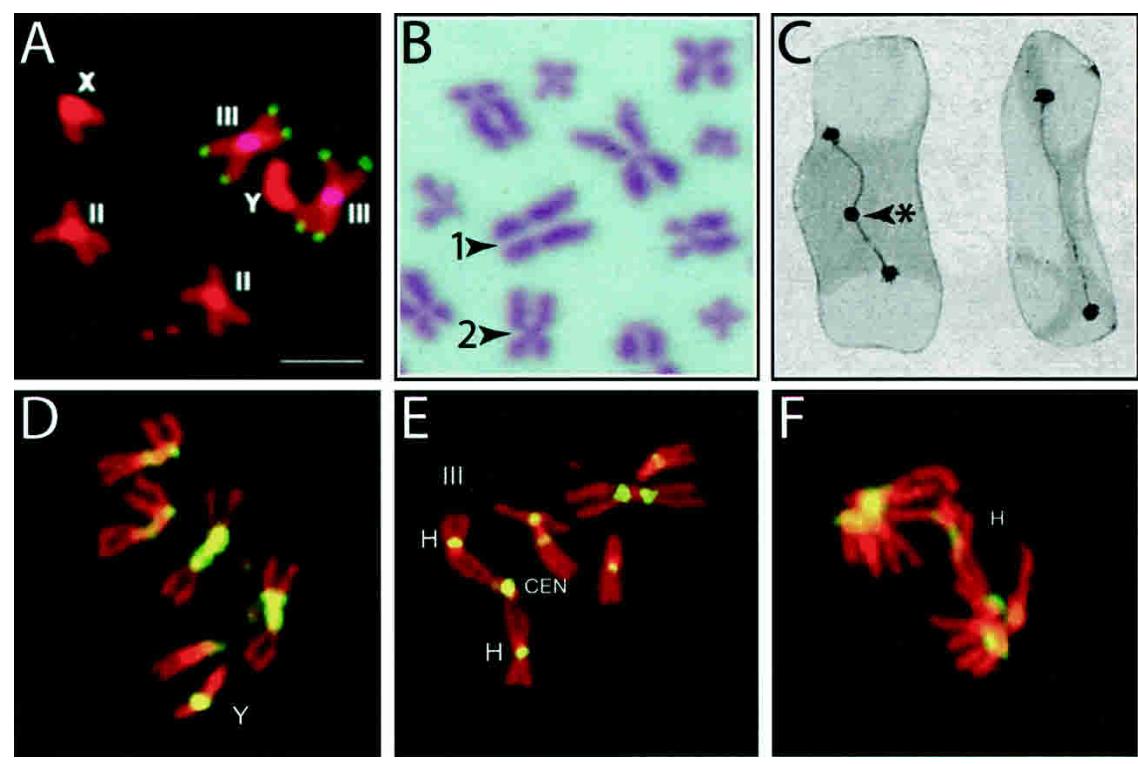

Figure 4. Sister chromatid cohesion at heterochromatic/repeated DNA in various eukaryotes. (A) Karyotype of a wild-type $D$. melanogaster male third instar larval neuroblast. Cell blocked in prometaphase with colchicine showing well-condensed chromosomes (red) are hybridized with telomeric (green) and centromeric (blue) probes for chromosome III. Note that cohesion between the arms of the heterochromatic $\mathrm{Y}$ chromosome is maintained, even though cohesion between the arms of other chromosomes is lost. Figure reproduced from Queiroz-Machado et al. (2001) with permission from Chromosoma (C) 2001 Springer). (B) Chromosomes from a human cell at the metaphase-anaphase junction. Loss of sister-chromatid cohesion follows a genetically predetermined sequence in mammals; chromosomes having the least pericentromeric repeated/heterochromatic DNA generally separate first, whereas those having most separate last. Chromosomes marked with 1 and 2 are examples of an early separating chromosome and a chromosome with persistent cohesion, respectively. Picture courtesy of Baldev K. Vig. (C) Early drawings of Schizosaccharomyces octosporus undergoing meiotic anaphase I made by Alexandre Guilliermond in 1917. The cell on the left is in late anaphase and the cell on the right is in telophase. The nucleolus (marked with a star) persists in the middle of the elongating spindle in anaphase, whereas most of the nucleus is already separated at this stage (the black dots at the spindle poles). The nucleolus is eventually partitioned to both nuclei in telophase (right cell). Figure reproduced from Guilliermond (1917; Figs. 12-13) with permission from Annales de 1'Institut Pasteur (C) 1917 Institut Pasteur). $(D-F)$ Heterochromatin causes persistent cohesion between sister chromatids. DNA is shown in red (propidium iodide) and heterochromatic regions are shown in yellow (in situ hybridization). All images correspond to squashed preparations of $D$. melanogaster third instar neuroblasts prepared in the presence $(D, E)$ or absence $(F)$ of colchicine, and show that the heterochromatic regions separate later than euchromatic regions. (D) Wild-type male cell ([Y] Y chromosome). (E) Female cell carrying a C(2)EN chromosome that has two blocks of extra heterochromatin (H), as well as a functional centromere (CEN). Note that the C(2)EN sister chromatids show strong pairing at the extra $\mathrm{H}$ regions. $(F)$ Cell carrying a $\mathrm{C}(2) \mathrm{EN}$ chromosome in anaphase showing that the extra heterochromatin $(\mathrm{H})$ remains tightly paired until late anaphase. The $\mathrm{C}(2) \mathrm{EN}$ regions of heterochromatin eventually resolve and segregate normally. $A$ and $D-F$ are courtesy of Paula Coelho, Joana Quiroz-Machado, and Claudio E. Sunkel.

The first indication that cohesin removal—or inactivation-is not sufficient for the segregation of repetitive DNA came from the analysis of cells deficient in FEAR network activity. It has been shown some time ago that cdc14 mutants exhibited defects in the separation of the nucleolus (Granot and Snyder 1991). A recent extensive characterization of the role of Cdc14 in chromosome segregation revealed that Cdc14 activated during early anaphase by the FEAR network was necessary for the efficient segregation of the rDNA array and also telomeres, but not for the segregation of other regions of the genome (D'Amours et al. 2004; Sullivan et al. 2004; Torres-Rosell et al. 2004). Strikingly, the rDNA segregation defect of $c d c 14$ and FEAR network mutants is not bypassed by either the absence or inactivation of cohesin ( $\mathrm{D}^{\prime}$ Amours et al. 2004; Sullivan et al. 2004). Taken together, these observations indicate that other types of sister-chromatid linkages exist at the rDNA, and that Cdc14 and the FEAR network are responsible for the dissolution of these linkages. It is worth noting that this cohesin-independent cohesion also exists between homologs during meiosis I (Buonomo et al. 2003), which could be mediated by the same sister linkages that are observed during mitosis or through direct homolog-homolog interactions.
Although the nature of the cohesion between sister chromatids (and possibly homologs) at repetitive DNA remains unknown, we do know how Cdc14 released by the FEAR network promotes the dissolution of rDNA linkages. Studies of mutants defective in condensin, a protein complex structurally similar to cohesin and involved in chromosome condensation, showed that they have nucleolar and telomeric segregation defects very similar to that of FEAR network mutants (Freeman et al. 2000; Bhalla et al. 2002). This observation raised the possibility that the FEAR network and condensin act together to mediate rDNA segregation in anaphase. Several lines of evidence support this view. First, the anaphasespecific enrichment of condensin in the nucleolus depends on Cdc14 released by the FEAR network (D'Amours et al. 2004; Wang et al. 2004). Second, overexpression of Cdc14 is sufficient to induce condensin enrichment in the nucleolus and rDNA separation in stages of the cell cycle when these events do not normally occur. Finally, inactivation of condensin prevents the separation of the rDNA in cells overexpressing Cdc14 (D'Amours et al. 2004). Mechanistically, the FEAR network may target condensin to the nucleolus or otherwise activate its segregation function by regulating the attachment of the ubiquitin-like protein SUMO to 
Ycs4 (a condensin subunit). Interestingly, there is a precedent for a regulatory role of SUMO in this process, as fruit flies deficient in the SUMO ligase Su(var)2-10 show a strong defect in chromosome condensation during mitosis (Hari et al. 2001). Strikingly, this defect is associated with a reduced fidelity in chromosome transmission, increased occurrence of anaphase bridging, and formation of melanotic tumors (Hari et al. 2001). Likewise, inactivation of the desumoylating enzyme Smt4 in budding yeast causes condensin localization and rDNA segregation defects similar to that of FEAR network mutants (Strunnikov et al. 2001; D'Amours et al. 2004). The validation of this putative mechanism for regulating condensin localization and rDNA segregation awaits the identification of the sumoylation sites on Ycs4.

How could FEAR network-dependent regulation of condensin promote the segregation of repetitive DNA? A key issue with the segregation of ChrXII, the rDNA-bearing chromosome, is the reduction of its length. ChrXII is the longest chromosome in yeast, and it is therefore important for cells to make sure that the rDNA-bearing arm of this chromosome (the longest arm) is shortened to a length at least half the length of the anaphase spindle. The FEAR network regulates this process together with condensin in at least two ways, conventional chromosome condensation and large-scale chromosome compaction/organization.

Chromosome condensation. The rDNA remains condensed for a longer period of time than any other chromosomal regions in yeast (Guacci et al. 1994). This is likely to reflect the fact that complete segregation of ChrXII requires more time than that of other chromosomes because of its length. Cdc14 plays an important role in this process because, in the absence of this protein, cells do not maintain condensation at the rDNA during anaphase (Guacci et al. 1994). Overexpression of Cdc14 is also sufficient to induce rDNA condensation in metaphase-arrested cells (Sullivan et al. 2004). The function of Cdc14 in chromosome condensation likely reflects its activation by the FEAR network, as the MEN component Cdc15 is not required for this process (Guacci et al. 1994). Nevertheless, a role of the FEAR network in chromosome condensation remains to be proven formally, as no other FEAR network mutants have been tested for their contribution to this process.

Chromosome compaction/organization. The functional relationship between chromosome length reduction and segregation appears to be more complex than a simple process of chromosome shortening by conventional condensation (i.e., condensation typically occurring at euchromatic loci). The initial observation supporting this idea came from the study of cells defective in the Ipl1-Sli15 complex, the yeast homolog of the human Aurora B-Incenp complex (D'Amours et al. 2004; Sullivan et al. 2004). In these cells, anaphase-specific rDNA condensation is completely defective (Lavoie et al. 2004), yet these mutants show only a modest reduction in the efficiency of ChrXII segregation (i.e., 10\%$20 \%$ missegregation; Sullivan et al. 2004). This contrasts with the severity of the rDNA segregation defect seen in cdc14 mutants $(-80 \%-90 \%)$ and indicates that the chromosome condensation defect of FEAR network mutants cannot fully explain their rDNA segregation defect (Granot and Snyder 1991; D'Amours et al. 2004; Sullivan et al. 2004; Torres-Rosell et al. 2004). This conclusion is consistent with the finding that overexpression of Cdc14 in metaphase-arrested cells can promote rDNA separation when condensation is completely eliminated by inactivation of cohesin and Ipl1 (in a mcd-1 ipl1-123 mutant; D'Amours et al. 2004). In contrast, loss of condensin in metaphase-arrested Cdc14 overproducing cells does prevent rDNA separation (D'Amours et al. 2004). Taken together, these observations indicate that the role of condensin and the FEAR network in chromosome condensation can be separated genetically from their role in chromosome segregation. Furthermore, these results indicate that aspects of large-scale chromosome organization other than condensation, at least taken in its classical definition, are required for rDNA segregation.

Why the rDNA array imposes a requirement for mechanisms in addition to cohesin removal for efficient segregation is not clear at present. If the role of Cdc14 in rDNA segregation was restricted to shortening the rDNA array to a length smaller than half the mitotic spindle, one might expect that the rDNA array would eventually separate-by passive diffusion-in the absence of cohesin activity. Yet, cohesin-deficient cells maintained in metaphase do not separate their rDNA array (D'Amours et al. 2004). Thus, something else, also under the control of the FEAR network and condensin, must hold the sister chromatids together at the rDNA array. Interestingly, neither increased recombination nor the heterochromatic nature of the rDNA locus appear to be responsible for creating these linkages ( $\mathrm{D}^{\prime}$ Amours et al. 2004; Sullivan et al. 2004). Perhaps catenates that need specialized mechanisms for their removal are enriched at repetitive DNA. However, cdc14 mutants do not show defects in topoisomerase II (Top2) decatenation activity (Koshland and Hartwell 1987). Furthermore, high levels of Cdc14 can induce rDNA separation in metaphase-arrested top2 mutants (D'Amours et al. 2004) and overexpression of Top 2 does not bypass the segregation defect of condensin mutants (Bhalla et al. 2002). It is possible that the relative chromosomal positioning (i.e., centromere proximal vs. distal) of the rDNA array or its position in the nucleus (near the nuclear envelope) plays a role in its late segregation. Identifying why a special form of cohesion is present at repetitive regions is an important question for the future.

It is tempting to speculate that a condensation-independent function of the condensin complex also exists in higher eukaryotes. Chromosome segregation defects are observed in most, if not all, eukaryotes where condensin mutants have been identified (Saka et al. 1994; Strunnikov et al. 1995; Bhat et al. 1996; Sutani et al. 1999; Freeman et al. 2000; Lavoie et al. 2000, 2002; Steffensen et al. 2001; Bhalla et al. 2002; Hagstrom et al. 2002). Segregation of repetitive DNA may also require mechanisms in addition to cohesin removal in higher eukaryotes. Chicken cells defective in the $\operatorname{Rad} 21 / \mathrm{Mcd} 1 / \mathrm{Scc} 1$ subunit 
of cohesin often maintain cohesion between the telomeres or centromeres, two regions containing highly repetitive DNA (Sonoda et al. 2001). Likewise, Drosophila polo mutants (Polo encodes the Drosophila homolog of yeast $\mathrm{Cdc5}$ ) have been reported to maintain cohesion at their telomeres during anaphase, just like FEAR network mutants in yeast (Donaldson et al. 2001). A similar persistence of cohesion at telomeres-the trenino phenotype-has been observed in flies deficient for the ubiquitin conjugating enzyme UbcD1 (Cenci et al. 1997). Interestingly, in crane-fly cells, sister telomeres appear to be held together by special elastic tethers that may need to be lost during anaphase for efficient segregation of sister chromatids (LaFountain et al. 2002). A recent study using human cells showed that the segregation of telomeres requires the activity of Tankyrase 1, a telomerase-associated factor with poly(ADP-ribose) polymerase activity (Dynek and Smith 2004). In cells deficient for this enzyme, centromeres as well as chromosome arms segregate efficiently, whereas telomeres remain associated. This function of Tankyrase 1 requires its poly(ADP-ribose) polymerase activity, but the target of this post-translational modification is still unknown. More work is needed to determine whether a cohesin-independent, Cdc14-dependent segregation pathway exists in higher eukaryotes.

\section{The role of Cdc14 and the FEAR network during the meiotic cell cycle}

The meiotic cell cycle is a specialized division program, in that a single round of DNA replication is followed by two chromosome segregation phases (for review, see Nasmyth 2002). The role of Cdc14 and the FEAR network in exit from meiosis I is similar to their role in mitosis; they are required for the inactivation of $\mathrm{Clb}-$ CDKs, although the requirement for CDK inactivation during meiosis I appears more acute than during mitosis (Buonomo et al. 2003; Marston et al. 2003). However, during meiosis, Cdc14 is also essential to coordinate the specialized division events, a function that is unique to the meiotic cell cycle. Insight into this role of the FEAR network came from two studies that examined the phenotype of $c d c 14$ and FEAR network mutants progressing in the meiotic cell cycle. Instead of arresting in anaphase I with homologous chromosomes segregated, $c d c 14$ and FEAR network mutants exhibit a mixed chromosome segregation pattern, which is characterized by some chromosomes segregating in a meiosis I-like pattern and others segregating in a meiosis II-like pattern (Klapholz and Esposito 1980; Sharon and Simchen 1990; Kamieniecki et al. 2000; Zeng and Saunders 2000; Buonomo et al. 2003; Marston et al. 2003). This unusual chromosome segregation pattern appears to result from meiotic events being uncoupled (Buonomo et al. 2003; Marston et al. 2003). Despite cells arresting in anaphase I, meiosis II chromosome segregation events continue to occur, leading to some chromosomes undergoing both meiotic divisions on the same anaphase I spindle. Thus, it appears that Cdc14 and the FEAR network ensure the sequential occurrence of the two meiotic divisions and their taking place on two sequentially built spindles. How does Cdc14 and the FEAR network accomplish this? Probably by antagonizing meiotic CDK activity. The down-regulation of meiotic CDK activity promotes meiosis I spindle disassembly which simulatenously creates conditions that are incompatible with chromosome segregation.

\section{Future perspectives}

The perennial question for the mitotic exit field has been whether the discoveries made in budding yeast can be applied to higher eukaryotes. For instance, it is still unclear how a system adapted for, and making use of an asymmetric mode of cell division could be used in a symmetric fission-based division system such as the one used in metazoans. Despite these differences, mammalian homologs of many MEN components, including Dbf2 (NDR1 and LATS1/h-WARTS; Millward et al. 1995; Nishiyama et al. 1999; Tao et al. 1999), Mob1 (MOB4; Luca and Winey 1998), Nud1 (Centriolin; Gromley et al. 2003), Bub2 (GAPCenA; Cuif et al. 1999); Cdc5 (PLK1; Clay et al. 1993; Lake and Jelinek 1993; Golsteyn et al. 1994) and Cdc14 (CDC14A and CDC14B; Li et al. 1997), have been identified (Table 1). Interestingly, it appears that these proteins function in cytokinesis rather than mitotic CDK inactivation in higher eukaryotes. The role of MEN components in cytokinesis appears to be conserved through evolution, as $c d c 14$ mutants in $S$. pombe, Caenorhabditis elegans, and humans have a striking defect in this process (Cueille et al. 2001; Trautmann et al. 2001; Gruneberg et al. 2002; Mailand et al. 2002).

The existence of a network analogous to the FEAR network in higher eukaryotes has not been demonstrated yet. Nevertheless, orthologs of all members of the FEAR network, with the notable exception of Slk19, have been identified in other yeasts and multicellular eukaryotes. Furthermore, at least two phenomena controlled by the FEAR network in yeast are conserved in mammals. First, the Ipl1-Sli15 complex homolog AIRK2-INCENP translocates from kinetochores to the spindle midzone during anaphase (Eckley et al. 1997; Adams et al. 2000), and abrogation of this translocation is believed to cause defects in cytokinesis (Eckley et al. 1997). Furthermore, $C$. elegans Cdc14 has been implicated in spindle midzone formation through dephosphorylation of the kinesin ZEN4 (Gruneberg et al. 2002). Second, segregation of repetitive/heterochromatic genomic regions seems to also occur late during mitosis in multicellular eukaryotes (discussed above). Whether the FEAR network homologs function in the regulation of these processes is unknown. However, our detailed knowledge of the roles of the FEAR network in Ipll-complex relocalization and repetitive DNA segregation in yeast provides an excellent stepping stone to address the existence of analogous regulatory processes in higher eukaryotes.

A key issue for our understanding of the FEAR network is the identification of substrates for Cdc14. We 
know one mechanism whereby Cdc14 released by the FEAR network stimulates MEN activity (through Cdc15 dephosphorylation) and we also know how Cdc14 targets the Ipl1-Sli15 complex to the spindle midzone (through dephosphorylation of Sli15). However, we do not know how Cdc14 accomplishes its other functions during early anaphase. It will be interesting to see whether components of the sumoylation machinery (D'Amours et al. 2004; Wang et al. 2004) or regulators of microtubuledependent forces, such as Kar9 (Liakopoulos et al. 2003; Maekawa et al. 2003; Ross and Cohen-Fix 2004) are dephosphorylated by Cdc14.

In closing, we note that FEAR network components and Cdc14 are not only required for the segregation of repetitive DNA, nuclear positioning, and localization of spindle midzone proteins, but also for the maintenance of genomic integrity and viability (Hartwell and Smith 1985; D'Amours et al. 2004). As chromosome instability is tightly linked to tumorigenesis, it is possible that mutations in components of the FEAR network contribute to malignant transformation. Determining whether components of the FEAR network are mutated in human cancers should provide insight into this question.

\section{Acknowledgments}

We apologize to our colleagues whose work could not be cited due to space constrains. We thank members of the Amon lab for their critical reading of the manuscript. We would also like to thank Baldev K. Vig, Paula Coelho, Joana Quiroz-Machado, and Claudio E. Sunkel for their kind gift of pictures. Damien D'Amours is a Damon Runyon Fellow supported by the Damon Runyon Cancer Research Foundation (DRG-1773-03). Work in A.A.'s laboratory is supported by a National Institute of Health grant (GM 56800). A.A. is an investigator of the Howard Hughes Medical Institute

\section{References}

Adams, R.R., Wheatley, S.P., Gouldsworthy, A.M., KandelsLewis, S.E., Carmena, M., Smythe, C., Gerloff, D.L., and Earnshaw, W.C. 2000. INCENP binds the Aurora-related kinase AIRK2 and is required to target it to chromosomes, the central spindle and cleavage furrow. Curr. Biol. 10: 10751078.

Azzam, R., Chen, S.L., Shou, W., Mah, A.S., Alexandru, G., Nasmyth, K., Annan, R.S., Carr, S.A., and Deshaies, R.J. 2004. Phosphorylation by cyclin B-Cdk underlies release of mitotic exit activator Cdc14 from the nucleolus. Science 305: 516-519.

Bardin, A.J. and Amon, A. 2001. Men and sin: What's the difference? Nat. Rev. Mol. Cell. Biol. 2: 815-826.

Bardin, A.J., Visintin, R., and Amon, A. 2000. A mechanism for coupling exit from mitosis to partitioning of the nucleus. Cell 102: 21-31.

Bhalla, N., Biggins, S., and Murray, A.W. 2002. Mutation of YCS4, a budding yeast condensin subunit, affects mitotic and nonmitotic chromosome behavior. Mol. Biol. Cell 13: 632-645.

Bhat, M.A., Philp, A.V., Glover, D.M., and Bellen, H.J. 1996. Chromatid segregation at anaphase requires the barren product, a novel chromosome-associated protein that interacts with Topoisomerase II. Cell 87: 1103-1114.
Biggins, S. and Murray, A.W. 2001. The budding yeast protein kinase Ipl1/Aurora allows the absence of tension to activate the spindle checkpoint. Genes \& Dev. 15: 3118-3129.

Buonomo, S.B., Rabitsch, K.P., Fuchs, J., Gruber, S., Sullivan, M., Uhlmann, F., Petronczki, M., Toth, A., and Nasmyth, K. 2003. Division of the nucleolus and its release of CDC14 during anaphase of meiosis I depends on separase, SPO12, and SLK19. Dev. Cell 4: 727-739.

Buvelot, S., Tatsutani, S.Y., Vermaak, D., and Biggins, S. 2003. The budding yeast Ipl1/Aurora protein kinase regulates mitotic spindle disassembly. J. Cell. Biol. 160: 329-339.

Byers, B. and Goetsch, L. 1975. Behavior of spindles and spindle plaques in the cell cycle and conjugation of Saccharomyces cerevisiae. J. Bacteriol. 124: 511-523.

Carmena, M., Abad, J.P., Villasante, A., and Gonzalez, C. 1993. The Drosophila melanogaster dodecasatellite sequence is closely linked to the centromere and can form connections between sister chromatids during mitosis. I. Cell. Sci. 105: 41-50.

Cenci, G., Rawson, R.B., Belloni, G., Castrillon, D.H., Tudor, M., Petrucci, R., Goldberg, M.L., Wasserman, S.A., and Gatti, M. 1997. UbcD1, a Drosophila ubiquitin-conjugating enzyme required for proper telomere behavior. Genes \& Dev. 11: 863-875.

Clay, F.J., McEwen, S.J., Bertoncello, I., Wilks, A.F., and Dunn, A.R. 1993. Identification and cloning of a protein kinaseencoding mouse gene, Plk, related to the polo gene of Drosophila. Proc. Natl. Acad. Sci. 90: 4882-4886.

Cohen-Fix, O. and Koshland, D. 1999. Pds1p of budding yeast has dual roles: Inhibition of anaphase initiation and regulation of mitotic exit. Genes \& Dev. 13: 1950-1959.

Cohen-Fix, O., Peters, J.M., Kirschner, M.W., and Koshland, D. 1996. Anaphase initiation in Saccharomyces cerevisiae is controlled by the APC-dependent degradation of the anaphase inhibitor Pds1p. Genes \& Dev. 10:3081-3093.

Cueille, N., Salimova, E., Esteban, V., Blanco, M., Moreno, S., Bueno, A., and Simanis, V. 2001. Flp1, a fission yeast orthologue of the $S$. cerevisiae CDC14 gene, is not required for cyclin degradation or rum $1 \mathrm{p}$ stabilisation at the end of mitosis. J. Cell. Sci. 114: 2649-2664.

Cuif, M.H., Possmayer, F., Zander, H., Bordes, N., Jollivet, F., Couedel-Courteille, A., Janoueix-Lerosey, I., Langsley, G., Bornens, M., and Goud, B. 1999. Characterization of GAPCenA, a GTPase activating protein for Rab6, part of which associates with the centrosome. EMBO J. 18: 1772-1782.

D'Amours, D., Stegmeier, F., and Amon, A. 2004. Cdc14 and condensin control the dissolution of cohesin-independent chromosome linkages at repeated DNA. Cell 117: 455-469.

Dernburg, A.F., Sedat, J.W., and Hawley, R.S. 1996. Direct evidence of a role for heterochromatin in meiotic chromosome segregation. Cell 86: 135-146.

Donaldson, M.M., Tavares, A.A., Ohkura, H., Deak, P., and Glover, D.M. 2001. Metaphase arrest with centromere separation in polo mutants of Drosophila. J. Cell. Biol. 153: 663676.

Dynek, J.N. and Smith, S. 2004. Resolution of sister telomere association is required for progression through mitosis. Science 304: 97-100.

Eckley, D.M., Ainsztein, A.M., Mackay, A.M., Goldberg, I.G., and Earnshaw, W.C. 1997. Chromosomal proteins and cytokinesis: Patterns of cleavage furrow formation and inner centromere protein positioning in mitotic heterokaryons and mid-anaphase cells. J. Cell. Biol. 136: 1169-1183.

Freeman, L., Aragon-Alcaide, L., and Strunnikov, A. 2000. The condensin complex governs chromosome condensation and mitotic transmission of rDNA. J. Cell. Biol. 149: 811-824. 
Frenz, L.M., Lee, S.E., Fesquet, D., and Johnston, L.H. 2000. The budding yeast Dbf2 protein kinase localises to the centrosome and moves to the bud neck in late mitosis. J. Cell. Sci. 113: 3399-3408.

Golsteyn, R.M., Schultz, S.J., Bartek, J., Ziemiecki, A., Ried, T., and Nigg, E.A. 1994. Cell cycle analysis and chromosomal localization of human Plk1, a putative homologue of the mitotic kinases Drosophila polo and Saccharomyces cerevisiae Cdc5. J. Cell. Sci. 107: 1509-1517.

Gonzalez, C., Casal Jimenez, J., Ripoll, P., and Sunkel, C.E. 1991. The spindle is required for the process of sister chromatid separation in Drosophila neuroblasts. Exp. Cell. Res. 192: $10-15$.

Granot, D. and Snyder, M. 1991. Segregation of the nucleolus during mitosis in budding and fission yeast. Cell. Motil. Cytoskeleton 20: 47-54.

Gromley, A., Jurczyk, A., Sillibourne, J., Halilovic, E., Mogensen, M., Groisman, I., Blomberg, M., and Doxsey, S. 2003. A novel human protein of the maternal centriole is required for the final stages of cytokinesis and entry into $S$ phase. $I$. Cell. Biol. 161: 535-545.

Gruneberg, U., Glotzer, M., Gartner, A., and Nigg, E.A. 2002. The CeCDC-14 phosphatase is required for cytokinesis in the Caenorhabditis elegans embryo. J. Cell. Biol. 158: 901914.

Guacci, V., Hogan, E., and Koshland, D. 1994. Chromosome condensation and sister chromatid pairing in budding yeast. J. Cell. Biol. 125: 517-530.

Guilliermond, A. 1917. Sur la division nucléaire des levures. Ann. Inst. Pasteur 3: 107-113.

Hagstrom, K.A., Holmes, V.F., Cozzarelli, N.R., and Meyer, B.J. 2002. C. elegans condensin promotes mitotic chromosome architecture, centromere organization, and sister chromatid segregation during mitosis and meiosis. Genes \& Dev. 16: $729-742$.

Hari, K.L., Cook, K.R., and Karpen, G.H. 2001. The Drosophila $\mathrm{Su}($ var)2-10 locus regulates chromosome structure and function and encodes a member of the PIAS protein family. Genes \& Dev. 15: 1334-1348.

Hartwell, L.H. and Smith, D. 1985. Altered fidelity of mitotic chromosome transmission in cell cycle mutants of $S$. cerevisiae. Genetics 110: 381-395.

Hartwell, L.H., Culotti, J., Pringle, J.R., and Reid, B.J. 1974. Genetic control of the cell division cycle in yeast. Science 183: 46-51.

Hu, F., Wang, Y., Liu, D., Li, Y., Qin, J., and Elledge, S.J. 2001. Regulation of the Bub2/Bfa1 GAP complex by Cdc5 and cell cycle checkpoints. Cell 107: 655-665.

Jaspersen, S.L. and Morgan, D.O. 2000. Cdc14 activates cdc15 to promote mitotic exit in budding yeast. Curr. Biol. 10: 615618.

Jaspersen, S.L., Charles, J.F., Tinker-Kulberg, R.L., and Morgan, D.O. 1998. A late mitotic regulatory network controlling cyclin destruction in Saccharomyces cerevisiae. Mol. Biol. Cell 9: 2803-2817.

Jensen, S., Geymonat, M., Johnson, A.L., Segal, M., and Johnston, L.H. 2002. Spatial regulation of the guanine nucleotide exchange factor Ltel in Saccharomyces cerevisiae. J. Cell. Sci. 115: 4977-4991.

Kamieniecki, R.J., Shanks, R.M., and Dawson, D.S. 2000. Slk19p is necessary to prevent separation of sister chromatids in meiosis I. Curr. Biol. 10: 1182-1190.

Karpen, G.H., Le, M.H., and Le, H. 1996. Centric heterochromatin and the efficiency of achiasmate disjunction in Drosophila female meiosis. Science 273: 118-122.

Klapholz, S. and Esposito, R.E. 1980. Recombination and chro- mosome segregation during the single division meiosis in SPO12-1 and SPO13-1 diploids. Genetics 96: 589-611.

Koshland, D. and Hartwell, L.H. 1987. The structure of sister minichromosome DNA before anaphase in Saccharomyces cerevisiae. Science 238: 1713-1716.

LaFountain Jr., J.R., Cole, R.W., and Rieder, C.L. 2002. Partner telomeres during anaphase in crane-fly spermatocytes are connected by an elastic tether that exerts a backward force and resists poleward motion. J. Cell. Sci. 115: 1541-1549.

Lake, R.J. and Jelinek, W.R. 1993. Cell cycle- and terminal differentiation-associated regulation of the mouse mRNA encoding a conserved mitotic protein kinase. Mol. Cell. Biol. 13: $7793-7801$.

Lavoie, B.D., Tuffo, K.M., Oh, S., Koshland, D., and Holm, C. 2000. Mitotic chromosome condensation requires Brn1p, the yeast homologue of Barren. Mol. Biol. Cell 11: 1293-1304.

Lavoie, B.D., Hogan, E., and Koshland, D. 2002. In vivo dissection of the chromosome condensation machinery: Reversibility of condensation distinguishes contributions of condensin and cohesin. J. Cell. Biol. 156: 805-815.

- 2004. In vivo requirements for rDNA chromosome condensation reveal two cell-cycle-regulated pathways for mitotic chromosome folding. Genes \& Dev. 18: 76-87.

Lee, S.E., Frenz, L.M., Wells, N.J., Johnson, A.L., and Johnston, L.H. 2001. Order of function of the budding-yeast mitotic exit-network proteins Tem1, Cdc15, Mob1, Dbf2, and Cdc5. Curr. Biol. 11: 784-788.

Li, L., Ernsting, B.R., Wishart, M.J., Lohse, D.L., and Dixon, J.E. 1997. A family of putative tumor suppressors is structurally and functionally conserved in humans and yeast. I. Biol. Chem. 272: 29403-29406.

Liakopoulos, D., Kusch, J., Grava, S., Vogel, J., and Barral, Y. 2003. Asymmetric loading of Kar9 onto spindle poles and microtubules ensures proper spindle alignment. Cell 112: 561-574.

Lica, L.M., Narayanswami, S., and Hamkalo, B.A. 1986. Mouse satellite DNA, centromere structure, and sister chromatid pairing. J. Cell. Biol. 103: 1145-1151.

Luca, F.C. and Winey, M. 1998. MOB1, an essential yeast gene required for completion of mitosis and maintenance of ploidy. Mol. Biol. Cell 9: 29-46.

Maekawa, H. and Schiebel, E. 2004. Cdk1-Clb4 controls the interaction of astral microtubule plus ends with subdomains of the daughter cell cortex. Genes \& Dev. 18: 1709-1724.

Maekawa, H., Usui, T., Knop, M., and Schiebel, E. 2003. Yeast Cdk1 translocates to the plus end of cytoplasmic microtubules to regulate bud cortex interactions. EMBO J. 22: 438 449.

Mah, A.S., Jang, J., and Deshaies, R.J. 2001. Protein kinase Cdc15 activates the Dbf2-Mob1 kinase complex. Proc. Nat1. Acad. Sci. 98: 7325-7330.

Mailand, N., Lukas, C., Kaiser, B.K., Jackson, P.K., Bartek, J., and Lukas, J. 2002. Deregulated human Cdc14A phosphatase disrupts centrosome separation and chromosome segregation. Nat. Cell. Biol. 4: 317-322.

Marston, A.L., Lee, B.H., and Amon, A. 2003. The Cdc14 phosphatase and the FEAR network control meiotic spindle disassembly and chromosome segregation. Dev. Cell 4: 711 726.

McCollum, D. and Gould, K.L. 2001. Timing is everything: Regulation of mitotic exit and cytokinesis by the MEN and SIN. Trends Cell. Biol. 11: 89-95.

McGrew, J.T., Goetsch, L., Byers, B., and Baum, P. 1992. Requirement for ESP1 in the nuclear division of Saccharomyces cerevisiae. Mol. Biol. Cell 3: 1443-1454.

Millward, T., Cron, P., and Hemmings, B.A. 1995. Molecular 
cloning and characterization of a conserved nuclear serine(threonine) protein kinase. Proc. Natl. Acad. Sci. 92: 5022-5026.

Molero, G., Yuste-Rojas, M., Montesi, A., Vazquez, A., Nombela, C., and Sanchez, M. 1993. A cdc-like autolytic Saccharomyces cerevisiae mutant altered in budding site selection is complemented by SPO12, a sporulation gene. J. Bacteriol. 175: 6562-6570.

Molk, J.N., Schuyler, S.C., Liu, J.Y., Evans, J.G., Salmon, E.D., Pellman, D., and Bloom, K. 2004. The differential roles of budding yeast Tem $1 \mathrm{p}, \mathrm{Cdc} 15 \mathrm{p}$, and Bub2p protein dynamics in mitotic exit. Mol. Biol. Cell 15: 1519-1532.

Nash, P., Tang, X., Orlicky, S., Chen, Q., Gertler, F.B., Mendenhall, M.D., Sicheri, F., Pawson, T., and Tyers, M. 2001. Multisite phosphorylation of a CDK inhibitor sets a threshold for the onset of DNA replication. Nature 414: 514-521.

Nasmyth, K. 2002. Segregating sister genomes: The molecular biology of chromosome separation. Science 297: 559-565.

Nishiyama, Y., Hirota, T., Morisaki, T., Hara, T., Marumoto, T., Iida, S., Makino, K., Yamamoto, H., Hiraoka, T., Kitamura, N., et al. 1999. A human homolog of Drosophila warts tumor suppressor, h-warts, localized to mitotic apparatus and specifically phosphorylated during mitosis. FEBS Lett. 459: 159-165.

Parkes, V. and Johnston, L.H. 1992. SPO12 and SIT4 suppress mutations in DBF2, which encodes a cell cycle protein kinase that is periodically expressed. Nucleic Acids Res. 20: $5617-5623$.

Pearson, C.G. and Bloom, K. 2004. Dynamic microtubules lead the way for spindle positioning. Nat. Rev. Mol. Cell. Biol. 5: 481-492.

Pereira, G. and Schiebel, E. 2003. Separase regulates INCENPAurora B anaphase spindle function through Cdc14. Science 302: 2120-2124.

Pereira, G., Hofken, T., Grindlay, J., Manson, C., and Schiebel, E. 2000. The Bub2p spindle checkpoint links nuclear migration with mitotic exit. Mol. Cell 6: 1-10.

Pereira, G., Manson, C., Grindlay, J., and Schiebel, E. 2002. Regulation of the Bfa1p-Bub2p complex at spindle pole bodies by the cell cycle phosphatase Cdc14p. I. Cell. Biol. 157: 367-379.

Petersen, J. and Hagan, I.M. 2003. S. pombe aurora kinase/survivin is required for chromosome condensation and the spindle checkpoint attachment response. Curr. Biol. 13: 590-597.

Pimpinelli, S. and Ripoll, P. 1986. Nonrandom segregation of centromeres following mitotic recombination in Drosophila melanogaster. Proc. Nat1. Acad. Sci. 83: 3900-3903.

Queiroz-Machado, J., Perdigao, J., Simoes-Carvalho, P., Herrmann, S., and Sunkel, C.E. 2001. tef: A mutation that causes telomere fusion and severe genome rearrangements in Drosophila melanogaster. Chromosoma 110: 10-23.

Ross, K.E. and Cohen-Fix, O. 2004. A role for the FEAR pathway in nuclear positioning during anaphase. Dev. Cell 6: 729735.

Rudd, M.K., Mays, R.W., Schwartz, S., and Willard, H.F. 2003. Human artificial chromosomes with $\alpha$ satellite-based de novo centromeres show increased frequency of nondisjunction and anaphase lag. Mol. Cell. Biol. 23: 7689-7697.

Saka, Y., Sutani, T., Yamashita, Y., Saitoh, S., Takeuchi, M., Nakaseko, Y., and Yanagida, M. 1994. Fission yeast cut3 and cut 14, members of a ubiquitous protein family, are required for chromosome condensation and segregation in mitosis. EMBO J. 13: 4938-4952.

Seshan, A., Bardin, A.J., and Amon, A. 2002. Control of Lte1 localization by cell polarity determinants and Cdc14. Curr.
Biol. 12: 2098-2110.

Shah, R., Jensen, S., Frenz, L.M., Johnson, A.L., and Johnston, L.H. 2001. The Spo12 protein of Saccharomyces cerevisiae: A regulator of mitotic exit whose cell cycle-dependent degradation is mediated by the anaphase-promoting complex. Genetics 159: 965-980.

Sharon, G. and Simchen, G. 1990. Mixed segregation of chromosomes during single-division meiosis of Saccharomyces cerevisiae. Genetics 125: 475-485.

Shirayama, M., Matsui, Y., and Toh, E.A. 1994. The yeast TEM1 gene, which encodes a GTP-binding protein, is involved in termination of M phase. Mol. Cell. Biol. 14: 7476-7482.

Shou, W., Seol, J.H., Shevchenko, A., Baskerville, C., Moazed, D., Chen, Z.W., Jang, J., Charbonneau, H., and Deshaies, R.J. 1999. Exit from mitosis is triggered by Tem1-dependent release of the protein phosphatase Cdc14 from nucleolar RENT complex. Cell 97: 233-244.

Shou, W., Sakamoto, K.M., Keener, J., Morimoto, K.W., Traverso, E.E., Azzam, R., Hoppe, G.J., Feldman, R.M., DeModena, J., Moazed, D., et al. 2001. Net1 stimulates RNA polymerase I transcription and regulates nucleolar structure independently of controlling mitotic exit. Mol. Cell 8: 4555.

Shou, W., Azzam, R., Chen, S.L., Huddleston, M.J., Baskerville, C., Charbonneau, H., Annan, R.S., Carr, S.A., and Deshaies, R.J. 2002. Cdc5 influences phosphorylation of Net1 and disassembly of the RENT complex. BMC Mol. Biol. 3: 3 .

Simanis, V. 2003. Events at the end of mitosis in the budding and fission yeasts. J. Cell. Sci. 116: 4263-4275.

Sohrmann, M., Schmidt, S., Hagan, I., and Simanis, V. 1998. Asymmetric segregation on spindle poles of the Schizosaccharomyces pombe septum-inducing protein kinase Cdc7p. Genes \& Dev. 12: 84-94.

Sonoda, E., Matsusaka, T., Morrison, C., Vagnarelli, P., Hoshi, O., Ushiki, T., Nojima, K., Fukagawa, T., Waizenegger, I.C. Peters, J.M., et al. 2001. Scc1/Rad21/Mcd1 is required for sister chromatid cohesion and kinetochore function in vertebrate cells. Dev. Cell 1: 759-770.

Steffensen, S., Coelho, P.A., Cobbe, N., Vass, S., Costa, M., Hassan, B., Prokopenko, S.N., Bellen, H., Heck, M.M., and Sunkel, C.E. 2001. A role for Drosophila SMC4 in the resolution of sister chromatids in mitosis. Curr. Biol. 11: 295307.

Stegmeier, F., Visintin, R., and Amon, A. 2002. Separase, polo kinase, the kinetochore protein Slk19, and Spo12 function in a network that controls Cdc14 localization during early anaphase. Cell 108: 207-220.

Stegmeier, F., Huang, J., Rahal, R., Zmolik, J., Moazed, D., and Amon, A. 2004. The replication fork block protein Fob1 functions as a negative regulator of the FEAR network. Curr. Biol. 14: 467-480.

Straight, A.F., Marshall, W.F., Sedat, J.W., and Murray, A.W. 1997. Mitosis in living budding yeast: Anaphase A but no metaphase plate. Science 277: 574-578.

Strunnikov, A.V., Hogan, E., and Koshland, D. 1995. SMC2, a Saccharomyces cerevisiae gene essential for chromosome segregation and condensation, defines a subgroup within the SMC family. Genes \& Dev. 9: 587-599.

Strunnikov, A.V., Aravind, L., and Koonin, E.V. 2001. Saccharomyces cerevisiae SMT4 encodes an evolutionarily conserved protease with a role in chromosome condensation regulation. Genetics 158: 95-107.

Sullivan, M. and Uhlmann, F. 2003. A non-proteolytic function of separase links the onset of anaphase to mitotic exit. Nat. Cell. Biol. 5: 249-254.

Sullivan, M., Lehane, C., and Uhlmann, F. 2001. Orchestrating 
anaphase and mitotic exit: Separase cleavage and localization of Slk19. Nat. Cell. Biol. 3: 771-777.

Sullivan, M., Higuchi, T., Katis, V.L., and Uhlmann, F. 2004. Cdc14 phosphatase induces rDNA condensation and resolves cohesin-independent cohesion during budding yeast anaphase. Cell 117: 471-482.

Surana, U., Amon, A., Dowzer, C., McGrew, J., Byers, B., and Nasmyth, K. 1993. Destruction of the CDC28/CLB mitotic kinase is not required for the metaphase to anaphase transition in budding yeast. EMBO J. 12: 1969-1978.

Sutani, T., Yuasa, T., Tomonaga, T., Dohmae, N., Takio, K., and Yanagida, M. 1999. Fission yeast condensin complex: Essential roles of non-SMC subunits for condensation and Cdc2 phosphorylation of Cut3/SMC4. Genes \& Dev. 13: 2271-2283.

Tanaka, T.U., Rachidi, N., Janke, C., Pereira, G., Galova, M., Schiebel, E., Stark, M.J., and Nasmyth, K. 2002. Evidence that the Ipl1-Sli15 (Aurora kinase-INCENP) complex promotes chromosome bi-orientation by altering kinetochorespindle pole connections. Cell 108: 317-329.

Tao, W., Zhang, S., Turenchalk, G.S., Stewart, R.A., St John, M.A., Chen, W., and Xu, T. 1999. Human homologue of the Drosophila melanogaster lats tumour suppressor modulates CDC2 activity. Nat. Genet. 21: 177-181.

Tinker-Kulberg, R.L. and Morgan, D.O. 1999. Pds1 and Esp1 control both anaphase and mitotic exit in normal cells and after DNA damage. Genes \& Dev. 13: 1936-1949.

Torres-Rosell, J., Machin, F., Jarmuz, A., and Aragon, L. 2004. Nucleolar segregation lags behind the rest of the genome and requires Cdc $14 \mathrm{p}$ activation by the FEAR network. Cell Cycle 3: 496-502.

Toyn, J.H. and Johnston, L.H. 1994. The Dbf2 and Dbf20 protein kinases of budding yeast are activated after the metaphase to anaphase cell cycle transition. EMBO J. 13: 1103-1113.

Trautmann, S., Wolfe, B.A., Jorgensen, P., Tyers, M., Gould, K.L., and McCollum, D. 2001. Fission yeast Clp1p phosphatase regulates $\mathrm{G} 2 / \mathrm{M}$ transition and coordination of cytokinesis with cell cycle progression. Curr. Biol. 11: 931-940.

Ubersax, J.A., Woodbury, E.L., Quang, P.N., Paraz, M., Blethrow, J.D., Shah, K., Shokat, K.M., and Morgan, D.O. 2003. Targets of the cyclin-dependent kinase Cdk1. Nature 425: 859-864.

Vig, B.K. 1982. Sequence of centromere separation: Role of centromeric heterochromatin. Genetics 102: 795-806.

- 1987. Sequence of centromere separation: A possible role for repetitive DNA. Mutagenesis 2: 155-159.

Visintin, R. and Amon, A. 2001. Regulation of the mitotic exit protein kinases Cdc15 and Dbf2. Mol. Biol. Cell. 12: 29612974.

Visintin, R., Craig, K., Hwang, E.S., Prinz, S., Tyers, M., and Amon, A. 1998. The phosphatase Cdc14 triggers mitotic exit by reversal of Cdk-dependent phosphorylation. Mol. Cell 2: 709-718.

Visintin, R., Hwang, E.S., and Amon, A. 1999. Cfil prevents premature exit from mitosis by anchoring Cdc14 phosphatase in the nucleolus. Nature 398: 818-823.

Visintin, R., Stegmeier, F., and Amon, A. 2003. The role of the polo kinase Cdc5 in controlling Cdc14 localization. Mol. Biol. Cell 14: 4486-4498.

Wan, J., Xu, H., and Grunstein, M. 1992. CDC14 of Saccharomyces cerevisiae. Cloning, sequence analysis, and transcription during the cell cycle. J. Biol. Chem. 267: 11274-11280.

Wang, B.D., Yong-Gonzalez, V., and Strunnikov, A.V. 2004. Cdc14p/FEAR pathway controls segregation of nucleolus in $S$. cerevisiae by facilitating Condensin targeting to rDNA chromatin in anaphase. Cell Cycle 3: 960-967.
Warburton, P.E. and Cooke, H.J. 1997. Hamster chromosomes containing amplified human $\alpha$-satellite DNA show delayed sister chromatid separation in the absence of de novo kinetochore formation. Chromosoma 106: 149-159.

Winey, M., Mamay, C.L., O'Toole, E.T., Mastronarde, D.N., Giddings Jr., T.H., McDonald, K.L., and McIntosh, J.R. 1995. Three-dimensional ultrastructural analysis of the Saccharomyces cerevisiae mitotic spindle. J. Cell. Biol. 129: 16011615.

Yoshida, S. and Toh-e, A. 2002. Budding yeast Cdc5 phosphorylates Net1 and assists Cdc14 release from the nucleolus. Biochem. Biophys. Res. Commun. 294: 687-691.

Yoshida, S., Asakawa, K., and Toh-e, A. 2002. Mitotic exit network controls the localization of Cdc14 to the spindle pole body in Saccharomyces cerevisiae. Curr. Biol. 12: 944-950.

Zeng, X. and Saunders, W.S. 2000. The Saccharomyces cerevisiae centromere protein Slk19p is required for two successive divisions during meiosis. Genetics 155: 577-587.

Zeng, X., Kahana, J.A., Silver, P.A., Morphew, M.K., McIntosh, J.R., Fitch, I.T., Carbon, J., and Saunders, W.S. 1999. Slk19p is a centromere protein that functions to stabilize mitotic spindles. J. Cell. Biol. 146: 415-425. 


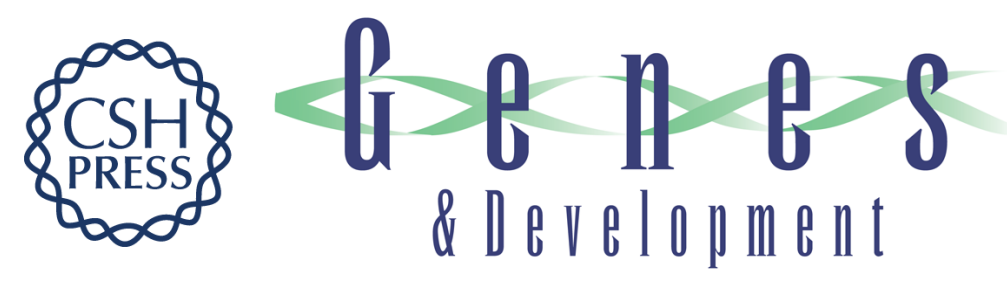

\section{At the interface between signaling and executing anaphase--Cdc14 and the FEAR network}

Damien D'Amours and Angelika Amon

Genes Dev. 2004, 18:

Access the most recent version at doi:10.1101/gad.1247304

References This article cites 117 articles, 65 of which can be accessed free at: http://genesdev.cshlp.org/content/18/21/2581.full.html\#ref-list-1

License

Email Alerting

Receive free email alerts when new articles cite this article - sign up in the box at the top Service right corner of the article or click here.

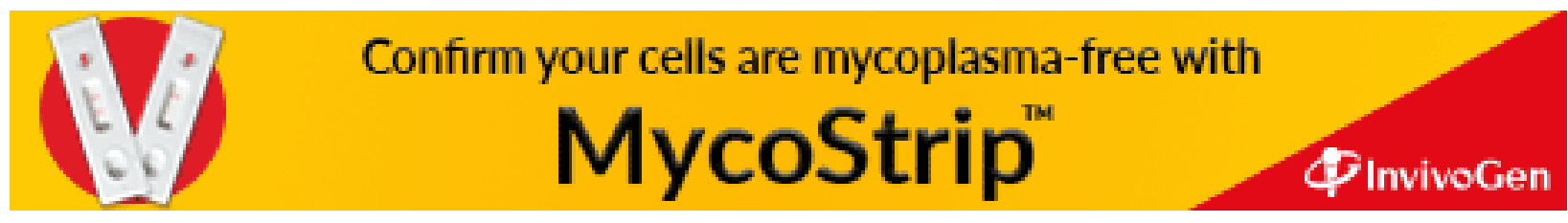

